\title{
Developing integrated mental health services for adults with ADHD
}

\section{Helen Crimlisk}

\begin{abstract}
SUMMARY
The article discusses the issues and challenges for mental health services in providing care for adults with attention-deficit hyperactivity disorder (ADHD). Based on work developed in Sheffield (UK), it describes the contribution that services integrated into community mental health teams may be able to provide. Given the likely increase in numbers of referrals of adults with ADHD (both 'graduates' from children's services and adults seeking diagnosis) and the pressures on resources, it is unlikely that current specialist services will be able to address the growing demand. A local service that can link with other mental health services and that has close links to primary care is most likely to provide a sustainable service model, but there are still considerable training needs for this model to be put into practice.
\end{abstract}

\section{DECLARATION OF INTERESTS}

None.

Attention-deficit hyperactivity disorder (ADHD) is a common, highly heritable disorder that normally presents in childhood. The characteristic features are inattention, impulsivity and usually (although not invariably) hyperactivity. It has previously been thought that the disorder resolves on approaching adulthood. More recent clinical and neurobiological studies, however, provide strong evidence for continuation into adulthood: $15 \%$ of affected children still fulfil criteria for ADHD at age 25, and 50\% have continued symptoms without the full disorder (i.e. are in partial remission) (Faraone 2006). ${ }^{\dagger}$

The impact of ADHD on children includes poor academic achievement, family discord, low self-esteem, poor life skills and risk of accidental injury (Harpin 2005). On approaching adolescence, individuals with ADHD are at increased risk of substance misuse, antisocial behaviour, early school termination and unstable employment. In adulthood, comorbid problems such as depression, anxiety and drug misuse are common and there is often enduring disability in functional domains which adversely affects quality of life (Mannuzza 2000). Low self-esteem, anxiety, previous poor achievement and poor organisational skills in people with ADHD all mitigate against their ability to access appropriate help. Many people with ADHD will develop additional mental health problems that need interventions from primary and secondary mental health teams. It is likely that a proportion of the current clients of these teams (and of other mental health teams such as forensic services and substance misuse teams) have underlying (unrecognised) ADHD (Almeida Montes 2007). For this reason, it is important that those working with primary and secondary mental health teams have an understanding of ADHD in adults.

\section{Background}

The concept of a syndrome comprising impairment in attention associated with hyperactivity has developed over more than 100 years. An interim concept of minimal brain disorder, and the demonstration of the beneficial effects of amphetamines on some symptoms in the 1930s, led to the inclusion of hyperkinetic reaction of childhood in DSM-II in 1968 (American Psychiatric Association 1968). This was developed into attention-deficit disorder with and without hyperactivity in DSMIII and attention-deficit/hyperactivity disorder in DSM-III-R (American Psychiatric Association 1980, 1987). Although controversial in earlier years, the diagnosis has now become broadly accepted among child psychiatrists and developmental paediatricians, and children with ADHD comprise a significant proportion of the caseload of most child and adolescent mental health services (CAMHS).

Twin studies indicate that ADHD is highly heritable, with about $75 \%$ of the variance in ADHD traits between individuals explained by genetic factors. The interactions between genes and environment are likely to be crucial, and $\mathrm{ADHD}$ is generally viewed as resulting from a complex mix of genetic and environmental factors (Thapar 2007). There is undoubtedly a higher incidence of ADHD in the context of intellectual disability, brain injury and prematurity, and an overlap with other neurodevelopmental disorders such as autism and specific learning difficulties.

Recent studies have looked at the symptoms associated with ADHD (McCarthy 2009). Although symptom count reduces with age in both people
Helen Crimlisk is consultant adult psychiatrist in a community mental health team in a deprived area of Sheffield. She coordinates the ADHD NICE guidelines group for Sheffield Health and Social Care NHS Foundation Trust, which has developed an integrated service for both 'graduate' patients from CAMHS or paediatrics and adults with newly diagnosed ADHD.

Correspondence Dr Helen Crimlisk, Eastglade CMHT, 1 Eastglade Crescent, Sheffield S12 40N, UK. Email: helen.crimlisk@ shsc.nhs.uk

${ }^{t}$ For an overview in Advances of the aetiology, presentation, diagnosis and management of $A D H D$ in adults see Janakiraman R, Benning T (2010) Attention-deficit hyperactivity disorder in adults, 16: 96-104. Ed. 
with ADHD and 'normal' controls, there is a persistent difference in symptom counts between people with and without ADHD in young adulthood. These residual symptoms cause problems because of the increased expectations placed on people as they mature. A meta-analysis of data on prevalence suggested an adult rate of around 2.5\% (Simon 2009). However, because of the difficulties in using criteria devised for children, the authors thought this likely to be an underestimate. There is undoubtedly a change in phenomenology with age: motor overactivity reduces, perhaps leaving some residual fidgetiness, while a sense of inner restlessness becomes more prominent.

\section{NICE guidelines}

The National Institute for Health and Clinical Excellence (NICE) clinical guideline CG72 clarifies a number of matters with regard to the role of adult mental health services in the diagnosis and management of adult ADHD (National Collaborating Centre for Mental Health 2008). The guideline development group took pains to demonstrate the validity of the diagnosis of $\mathrm{ADHD}$ in both children and adults.

Some of the key recommendations of CG72 regarding the management of $\mathrm{ADHD}$ in both children and adults are outlined in Box 1. In particular, NICE makes it clear that mental health trusts have a responsibility to provide assessment for adults, and treatment and care for those with the diagnosis. This is likely to include medication as first-line treatment, with cognitive-behavioural therapy and/or other multidisciplinary support for individuals with residual symptoms on medication or those who do not wish to take or cannot tolerate medication. In addition, mental health services are responsible for taking the lead in ensuring that training and education are provided for professionals in healthcare and other services (e.g. social care, police, youth offending teams, probation and education).

The guideline also highlights the importance of good transition arrangements to ensure smooth transfer of care from children's services to services for young adults. This can be a problem in the UK (Singh 2009) and it receives particular attention in the cross-government strategy document New Horizons (Department of Health 2009).

\section{Assessment}

Assessment of children is usually comprehensive and multidisciplinary, involving the child, the parents and the school, with direct observation of the child in different settings. Such observation is rarely practicable for adults, who are usually
BOX 1 Key recommendations for management of ADHD

- Setting up of specialist teams for diagnosis and management of ADHD in children, young people and adults

- Diagnosis should use DSM-IV or ICD-10 criteria and require at least moderate impairment of functioning and pervasive symptoms in more than one setting

- Diagnostic process should include an assessment of social, familial and educational/occupational needs

- Young people and adults with severe impairment should be offered medication as first-line treatment

- In adults, methylphenidate is generally the drug treatment of choice

- Medication should be part of a comprehensive treatment programme that addresses psychological, behavioural and educational or occupational needs

(National Collaborating Centre for Mental Health 2008)

assessed by a psychiatrist or other mental health specialist trained in ADHD, with supplementary collateral information from someone who knew the individual as a child (or at least documentary evidence such as school reports of behaviour during childhood) (Asherson 2005). Collateral information is necessary because an important component of the assessment is establishing whether symptoms had onset in childhood. The history should include developmental information and may be guided by checklists such as that proposed by the British Association of Psychopharmacology (BAP) (Box 2).

Rating scales or standardised diagnostic interviews may be used to assist diagnosis (for a review see Rösler 2006). The Wender Utah Rating Scale of current and retrospective symptoms has the practical advantage of being free (Ward 1993). It is important to emphasise (to patients as well) that these tools are not in themselves diagnostic. Symptoms should meet diagnostic criteria in DSM-IV (attention-deficit/hyperactivity disorder) or ICD-10 (hyperkinetic disorders) (Box 3), must be pervasive and must be associated with significant impairment in functioning. A suggested protocol covering the key issues to be addressed in the assessment of ADHD in adults is shown in Fig. 1. The necessity of undertaking a more detailed developmental history and obtaining collateral information means that this is likely to take longer than a standard psychiatric assessment. The United Kingdom Adult ADHD Network (UKAAN) has organised a series of workshops in association with the Royal College of Psychiatrists on the diagnosis and treatment of $\mathrm{ADHD}$ in adults, but conclusions have yet to be published. 
Assessment should also include a full mental state examination and consideration of differential diagnoses and additional (comorbid) mental health disorders. It may be helpful to think of ADHD as a risk factor for other disorders, such as depression, anxiety, substance misuse and personality disorder (Cumyn 2009). It is also more commonly seen in populations with neurodevelopmental disorders such as autism-spectrum disorder, dyslexia and other specific developmental disabilities (e.g. dyscalculia and dyspraxia) (Simonoff 2008). In general, $\mathrm{ADHD}$ is a persisting disorder and young people with a sustained diagnosis may continue to have significant difficulties in adulthood. These include continuing ADHD symptoms, personality disorders, emotional and social difficulties, substance misuse, no employment or underemployment, and involvement in crime (Biederman 2006).

\section{The diagnostic threshold}

The BAP checklist of ADHD symptoms (Box 2) includes problems with which many people will identify - ADHD can be considered the extreme end of a normally distributed behavioural trait. Inevitably, this makes applying a diagnostic cut-off controversial, but this is hardly a novel problem in psychiatry, as many other traits and symptoms are widely distributed across the population. One of the most important issues, therefore, is that of assessing functional impairment. Functioning should be

\section{History and mental state examination}

- Developmental history

- Family history: siblings/children/parents

- Past psychiatric/medical history

- Substance use

- Identification of key clinical characteristics of ADHD (Box 2)

- Assessment of risks

- Forensic history

- Assessment of functional impairment (work, education, relationships)

- Comorbid mental health problems

- Previous coping strategies/compensation mechanisms (e.g. alarms/reminders/deadlines, adaptability, reliance on others to assist organisation, sensation-seeking)

- Attitude to medication; sources of support and attitudes to these

2 Collateral information

- Interviewing family member, childhood acquaintance

- School reports

3 Rating scales for current symptoms and retrospective behaviour

For example:

- Wender Utah Rating Scale - retrospective and current symptoms

- Conners Adult ADHD Rating Scale

- Barkley's Current Symptoms Scale

Suggested protocol for assessment of ADHD in adults.
BOX 2 British Association of Psychopharmacology checklist for adult ADHD
- Lack of attention to detail or carelessness

- Inattention in tasks or activities the patient finds tedious

- Failure to follow instructions

- Starting many tasks whilst having difficulty finishing them

- Poor organisational skills

- Avoidance or dislike of, or inability to expend sustained mental effort

- Losing or misplacing things

- Ready distractibility

- Forgetfulness

- Fidgeting

- Restlessness or inability to sit still in low stimulus situations
- Difficulty listening
- Inappropriate or excessive activity or an internal feeling of restlessness or edginess

- Difficulty keeping quiet, talking out of turn

- Unfocused mental activity, difficulty turning thoughts off

- Blurting out responses, poor social timing in dialogue

- Trouble waiting if there's nothing to do

- Interrupting or intruding on others

- Irritability, impatience or frustration

- Affective lability or hot temper

- Stress intolerance

- Impulsivity or risk-taking in activities (From Nutt et al 2007, with permission) impaired in more than one realm of the patient's life (social, relationships, work and education).

Stimulant medication tends to increase alertness and focus in all people, regardless of the presence or absence of 'disorder' (hence its use in certain military and industrial situations). To avoid accusations of diagnosing or prescribing medication inappropriately, clinicians need to be diligent about applying a threshold that can be justified by demonstration of 'at least moderate impairment of functioning' (National Collaborating Centre for Mental Health 2008).

\section{Treatment options}

\section{Medication}

The NICE guideline CG72 recommends medication with methylphenidate as the first-line treatment for ADHD in adults (National Collaborating Centre for Mental Health 2008). Atomoxetine or dexamphetamine are second-line treatments after an adequate trial (minimum 6 weeks) of methylphenidate. For each of these drugs, the dose should be titrated against symptoms during the initial phase of treatment. It is particularly important to consider increasing the dose in young people who appear to be becoming resistant to the medication, as this may simply reflect the need for a higher dose as their weight increases. Table 1 shows normal doses and precautions.

Slow-release preparations of methylphenidate are useful because with once-daily tablets a more tailored release of medication is possible. Concerta XL has a peak effect 6-8h after ingestion, Equasym 
BOX 3 ADHD in children: DSM-IV (American Psychiatric Association 1994) and ICD-10 (World Health Organization 1992) diagnostic criteria
DSM-IV Attention-deficit/hyperactivity disorder (314)
- Six out of nine symptoms of inattention or six out of nine symptoms of hyperactivity/ impulsivity
ICD-10 Hyperkinetic disorders (F90)
Behaviour maladaptive, inconsistent with developmental level
- Symptoms present before age 7
- Impairment in at least two settings
- Symptom duration of at least 6 months
- Symptoms not accounted for by another disorder
- Symptoms of inattention, hyperactivity and impulsivity at home and at nursery or school
- $10>50$
- Onset before age 7
- Directly observed abnormality of attention and activity
- Symptom duration of at least 6 months
- Symptoms not accounted for by another disorder

XL and Medikinet XL have two peaks, at $30 \mathrm{~min}$ and 2-3 $\mathrm{h}$ after ingestion, so that clinical effectiveness can be achieved over a school or work day but has worn off before bedtime. Another medication, Adderall (mixed amphetamine salts), is licensed in the USA and Canada, but not in Europe. It too has a two-peak effect. Atomoxetine, a non-stimulant used in ADHD, does not have an immediate effect and (rather like antidepressants) needs to be taken for several weeks before assessing response. Atomoxetine should be favoured when there is a history of tics, a risk of psychosis or to avoid the use of stimulants where there is considered to be a risk of drug diversion (although this is not a common problem). Claims have been made for a number of other medications in resistant ADHD, but the evidence base for these is limited. For a fuller review, see Nutt et al (2007).

Current licensing of medications for ADHD in adults is limited and most medications will need to be prescribed off-label or at doses above current licensing limits, and this issue should be discussed with patients. Atomoxetine is licensed for adult $\mathrm{ADHD}$, but only if its prescription was initiated during childhood. The British Association of Psychopharmacology and NICE are clear in supporting the use of methylphenidate, atomoxetine and dexamphetamine in adult ADHD (Nutt 2007; National Collaborating Centre for Mental Health 2008). The prescription of controlled drugs such as stimulants can be time-consuming because of the requirements about the nature of the script and the development of shared-care protocols, although electronic prescribing (ePrescribing) has the potential to reduce this burden.

A medical history and appropriate physical examination (as a minimum, heart rate and blood pressure, and weight) should be undertaken before starting medication in adults. Cardiac symptoms or significant personal or family history of cardiac problems should prompt a fuller physical examination and electrocardiogram (ECG) prior to prescribing. While the patient is taking the medication, blood pressure, heart rate and weight should be monitored and the patient should be questioned about the presence of side-effects.

Atomoxetine has been associated with risks of liver dysfunction and suicidal ideation, so it is prudent to obtain liver function tests prior to treatment in anyone at risk and to monitor for increased suicidal ideation.

Once the patient is stabilised on medication, regular prescription can usually be undertaken by the general practitioner. This can be supported by the use of a shared-care protocol approved by the local primary care trust, whereby monitoring of mental state and side-effects are undertaken jointly by primary and secondary care.

Drug regimens in adult ADHD

\begin{tabular}{|c|c|c|c|}
\hline Generic name & Proprietary names & Dose range in adults (unlicensed) & Precautions \\
\hline \multirow[t]{4}{*}{ Methylphenidate } & Ritalin & $\begin{array}{l}5 \mathrm{mg} \text { three times a day, increased to maximum } \\
\text { of } 100 \mathrm{mg} / \text { day }\end{array}$ & \multirow{4}{*}{$\begin{array}{l}\text { Monitor for weight loss and growth retardation } \\
\text { Monitor for deterioration in mental state (depression, } \\
\text { irritability, psychosis) } \\
\text { Monitor heart rate and blood pressure } \\
\text { Monitor for tics }\end{array}$} \\
\hline & Concerta XL & $\begin{array}{l}18 \mathrm{mg} \text { once a day, increase in } 18 \mathrm{mg} \text { increments } \\
\text { weekly to maximum of } 108 \mathrm{mg} / \text { day }\end{array}$ & \\
\hline & Equasym XL & $\begin{array}{l}10 \mathrm{mg} \text { once a day, increase in } 10 \mathrm{mg} \text { increments } \\
\text { to maximum of } 100 \mathrm{mg} / \mathrm{day}\end{array}$ & \\
\hline & Medikinet XL & $\begin{array}{l}10 \mathrm{mg} \text { daily, increase in } 10 \mathrm{mg} \text { increments to } \\
\text { maximum of } 100 \mathrm{mg} / \mathrm{day}\end{array}$ & \\
\hline Atomoxetine & Strattera & $\begin{array}{l}40 \mathrm{mg} \text { once a day for } 7 \text { days, increased to } \\
80-100 \mathrm{mg} \text { once a day to a maximum of } \\
120 \mathrm{mg} / \text { day under supervision of specialist }\end{array}$ & $\begin{array}{l}\text { Liver function tests before initiation of treatment if } \\
\text { risk factors or alcohol misuse } \\
\text { Caution in those with depression or liver dysfunction }\end{array}$ \\
\hline Dexamphetamine & Dexedrine & $\begin{array}{l}5 \mathrm{mg} \text { twice a day, increased to maximum of } \\
60 \mathrm{mg} / \text { day }\end{array}$ & $\begin{array}{l}\text { Monitor for weight loss and growth retardation } \\
\text { Monitor for deterioration in mental state (depression, } \\
\text { irritability, psychosis) } \\
\text { Monitor heart rate and blood pressure } \\
\text { Monitor for tics }\end{array}$ \\
\hline
\end{tabular}




\section{Psychological interventions}

Although medication is the first-line intervention, NICE's CG72 makes it clear that it should be provided within the framework of a comprehensive treatment programme that addresses psychological, behavioural and educational or occupational needs (National Collaborating Centre for Mental Health 2008). This is likely to be best undertaken by a local service, such as an adult community mental health team, which is well informed about local provision within statutory services and the third sector.

There is some evidence in support of group cognitive-behavioural therapy (CBT) for adult ADHD (Bramham 2009; Solanto 2010). The CG72 guideline recommends it as the first-line psychological treatment, and it may be preferred by those who do not wish to use or cannot tolerate medication. The worksheets that accompany the book ADHD in Adults: A Psychological Guide to Practice (Young 2007) are a helpful resource in undertaking CBT for adult ADHD. In Sheffield, community mental health teams have used these as the basis of modules guiding CBT for young adults with the disorder (Box 4). A number of other psychosocial interventions may help people with ADHD (Box 5), but at present there is no evidence relating to their use.

\section{The transition from CAMHS}

As young patients approach the age at which they must move on from CAMHS (16-18 years, depending on local policy), NICE recommends that a review be undertaken to establish the rationale for continuing treatment into adulthood (National Collaborating Centre for Mental Health 2008). Many young people and their families will have experienced 'missed doses', and this may inform the assessment of the value of continued medication. The decision to continue or end medication may also be influenced by the impact of the individual's behaviour on the family and by the demands of the environment in which they are living. Someone in more formal education where prolonged concentration is necessary or in a job where impulsive behaviour would be particularly damaging may be more likely to wish to remain on medication than someone in a position where more flexibility is possible.

If the young patient has ongoing needs or medication is to be continued, arrangements should be made in conjunction with the patient and the family for transition to the appropriate adult services. It is suggested in CG72 that the care programme approach (CPA) system be used to facilitate smooth transfer.

\section{BOX 4 Modules used in Sheffield CBT programme for ADHD in young adults}
- Managing anger
- Time management and prioritising
- Regulating activity levels
- Self-esteem and negative thoughts
- Planning and impulsivity
- Use of substances - medication and others
- Memory and problem-solving
- Learning to learn effectively
- Choosing and keeping friends
- Keeping out of trouble
- Scary situations - managing anxiety

(Adapted from Young \& Bramham 2007)

A recent study (Taylor 2010) reviewing the service needs of young adults with ADHD found that 37\% of the clients at a paediatric neurodisability clinic were likely to need transition to adult mental health services. Good liaison between CAMHS, paediatrics and adult mental health services is essential if transition is to have a chance of working well at this critical point in a young person's life. However, a study of the transition of mental healthcare from child to adult services in several countries (Singh 2009) highlighted the low rates of good transition. Poor transition was related to low expectations of adult mental health services, lack of or nonadherence to cohesive transition protocols, strict age cut-offs, and patchy services for some disorders in adult services.

\section{BOX 5 Psychosocial interventions for adult} ADHD

- Cognitive-behavioural therapy (group or individual)

- Psychoeducational work

- Motivational/self-esteem work

- Substance misuse work

- Social inclusion work

- Occupational or vocational interventions

- Carer support

- Family interventions

- Transitional work

- Social skills training

- Liaison with employer or teacher/lecturer

- Life coaching

- Other psychotherapeutic input 


\section{Specialist $v$. generalist services}

The first specialist adult ADHD clinic in the UK was set up at London's Maudsley Hospital (Toone 1997) and is still active. In subsequent years, a handful of other adult ADHD clinics have been set up. As mentioned earlier, the NICE guideline published in 2008 made a number of recommendations regarding priorities for implementation in ADHD (Box 1), and specialist services have until now led the way in terms of service development. They provide expertise and the opportunity for much-needed research. As skills develop locally and the number of diagnosed adults increases, local services will need to consider the development of care pathways for:

- assessing adults for 'new' (diagnosis missed in childhood) ADHD

- transitional care of young people with $\mathrm{ADHD}$ from children's services

- continued management of adults with ADHD (both prescribing and monitoring medication, and recognising and treating comorbid conditions)
A number of different models of care have been developed to meet the NICE recommendations, some of which are considered in Table 2. The model chosen for service delivery in a particular region will depend on local conditions.

\section{Forensic and prison populations}

Recent research in the UK has confirmed the high prevalence of $\mathrm{ADHD}$ in prison populations (Rösler 2009). The strongest predictor for violent offending in male prison inmates is alcohol misuse, but ADHD symptoms are ranked second (Young 2010). Studies are underway to establish the prevalence of ADHD in forensic and substance misuse populations, and the figures are likely to be high. Identifying $\mathrm{ADHD}$ in these groups and finding the best way of offering helpful interventions will probably be a considerable challenge (for more details see Young 2011a). Diagnosing and treating ADHD in prison inmates may be logistically challenging, but there are indications that it may reduce illicit drug use and serious incidents (Young 2011b), making it not only beneficial to patients and fellow inmates but also cost-effective for the prison authorities.

\section{TABLE 2 Service delivery models}

\begin{tabular}{|c|c|c|}
\hline Model & Advantages & Disadvantages \\
\hline National/regional tertiary service & $\begin{array}{l}\text { Centres of excellence } \\
\text { Leaders in research and setting standards of service } \\
\text { Expertise as a result of dedicated clinicians with significant } \\
\text { experience }\end{array}$ & $\begin{array}{l}\text { Geographically distant, with limited local knowledge } \\
\text { Long-term follow-up not practical for many patients } \\
\text { Difficult for some patients to access } \\
\text { May attract an atypical client group because of the } \\
\text { distances involved and the additional difficulties associated } \\
\text { with obtaining funding for tertiary services }\end{array}$ \\
\hline $\begin{array}{l}\text { Neurodevelopmental disorders } \\
\text { service }\end{array}$ & $\begin{array}{l}\text { Experience in multidisciplinary assessment and diagnosis } \\
\text { Dedicated staff with specialist experience } \\
\text { Good links with neurology, paediatrics and intellectual disability } \\
\text { services } \\
\text { Good experience of liaison with education, vocational and } \\
\text { occupational rehabilitation }\end{array}$ & $\begin{array}{l}\text { Often have poor links with adult mental health services } \\
\text { May not have skills to manage comorbid disorders }\end{array}$ \\
\hline $\begin{array}{l}\text { Age-defined local transitional } \\
\text { service (e.g. for } 15 \text { - to } 25 \text {-year-olds) }\end{array}$ & $\begin{array}{l}\text { Good links with CAMHS, paediatrics and intellectual disability } \\
\text { services } \\
\text { Early intervention at a critical point in transition between } \\
\text { childhood and adulthood may have preventive value } \\
\text { Extra support at a time when other areas of support may be } \\
\text { lessening (e.g. education, family, children's services) }\end{array}$ & $\begin{array}{l}\text { Problems inherent in a transitional service (bottleneck at } \\
\text { age cut-off) } \\
\text { Perceived as ageist }\end{array}$ \\
\hline Local specialist ADHD team & $\begin{array}{l}\text { Local expertise } \\
\text { Easily accessible to service users } \\
\text { May be better placed to negotiate local arrangements with the } \\
\text { primary care trust (e.g. shared-care protocol) }\end{array}$ & $\begin{array}{l}\text { Likely to be small } \\
\text { May not see enough patients to develop expertise in more } \\
\text { complex cases } \\
\text { May not be truly multidisciplinary or integrated into teams }\end{array}$ \\
\hline $\begin{array}{l}\text { Local (CMHT) embedded ADHD } \\
\text { services }\end{array}$ & $\begin{array}{l}\text { Local and easily accessible to service users } \\
\text { Practical for a common disorder such as ADHD } \\
\text { Wide range of skills embedded within multidisciplinary team } \\
\text { Experience of managing comorbid problems } \\
\text { Good links with primary care }\end{array}$ & $\begin{array}{l}\text { May not see enough patients to develop expertise in more } \\
\text { complex cases } \\
\text { Limited skills and experience - will need training } \\
\text { Competition with other demands in CMHT }\end{array}$ \\
\hline Primary care-led service & $\begin{array}{l}\text { Practical and local } \\
\text { Best placed to oversee regular prescriptions and monitor patients } \\
\text { Use of shared care protocol can help primary care physicians } \\
\text { decide how best to prescribe and monitor medication and when } \\
\text { to seek help from secondary/tertiary services } \\
\text { Many general practices in the UK have access to psychological } \\
\text { interventions that could help the common comorbidities of } \\
\text { depression and anxiety }\end{array}$ & $\begin{array}{l}\text { Primary care physicians in the UK do not currently have the } \\
\text { skills to diagnose or initiate treatment } \\
\text { Most primary care physicians are do not work within } \\
\text { multidisciplinary teams that could assist management in } \\
\text { more complex cases } \\
\text { Will need access to more specialist advice regarding } \\
\text { medication regimens, management of side-effects and } \\
\text { discontinuation of medication }\end{array}$ \\
\hline
\end{tabular}




\section{The Sheffield model}

Several years ago, psychiatrists in Sheffield noted an increased demand for the assessment and management of ADHD in young people and adults. They recognised that comorbid mental illnesses are common and decided to encourage the professional development of staff within community mental heath teams rather than develop a specialist adult $\mathrm{ADHD}$ service or continue to routinely commission external services. Psychiatrists in each of the four CMHTs undertook training in assessment, and the members of the local NICE guidelines implementation group delivered brief training in adult ADHD to the CMHTs and professional groups within the trust. More detailed training days were run in conjunction with service users to augment learning in those working more closely with clients with $\mathrm{ADHD}$, enabling psychosocial interventions to be developed. These interventions are delivered by members of the CMHTs and/or a multidisciplinary, city-wide group Living with ADHD (Social Care Institute for Excellence 2011). Occupational therapists have particular skills in helping clients to manage their time, develop approaches to reduce difficulties within work or education, and access training or leisure services. An information leaflet (Sheffield Health and Social Care 2010) has been developed for patients, giving self-help tips (such as those in Box 6) and information relating to the NICE guideline, self-help groups and online resources such as the National Attention Deficit Disorder Information and Support Service (ADDISS; www. addiss.co.uk).

In 2009, there were 97 adult patients with a diagnosis of ADHD being cared for in the city (population 600 000). Two-thirds were 'graduate' patients from children's services or 'returnees' (diagnosed in childhood but lost to follow-up during adolescence) and one-third were diagnosed in adulthood (about a third of these were parents of children with ADHD). For historical reasons, the age of transition from CAMHS in Sheffield is 16, which may account for the high number of 'graduate' patients. The majority of the patients on the CMHT caseloads had significant social disadvantage: $40 \%$ had no qualifications from school, $70 \%$ had a history of exclusions from school, $45 \%$ were not in any form of employment or training, 30\% had comorbid drug or alcohol problems, and over 50\% had comorbid psychiatric disorders. There was a high level of contact with the police and courts: $28 \%$ had a history of convictions and $10 \%$ had spent time in prison or youth offender institutions.

In paediatric and CAMHS serivces, supplementary (usually nurse) prescribers are able to work under the supervision of doctors to prescribe medications, monitor side-effects and change dosage regimens. A business case is currently being developed to extend this model to adult services. The training required is available from a number of universities and generally involves a day-release course lasting about 6 months, with a requirement for additional learning in practice.

Work has been undertaken in developing transition protocols and we are currently piloting a joint-handover transition clinic with colleagues from children's services (for details, see Social Care Institute for Excellence 2011).

Liaison with local voluntary sector agencies such as Family Action (www.family-action.org.uk), which delivers interventions to parents of children with $\mathrm{ADHD}$ in the city, has been invaluable and we have also liaised with local and national self-help groups.

A care pathway has been agreed (Fig. 2) and a shared-care protocol has been negotiated with the primary care trust to enable prescribing to be taken over by general practitioners when patients are stabilised on medication (this was based on a very similar protocol previously negotiated between CAMHS/paediatrics and the primary care trust). Monitoring of patients is currently undertaken jointly by primary and secondary care at 6 -month intervals (details available on request).

\section{B0X 6 Self-help: 15 tips for living with your ADHD}

Tell people about your diagnosis

Ask for help from your friends and family

Get feedback about how you affect others

Use structure and prioritise

Reward yourself when things go well

Respond to boring tasks quickly

Accept that some things will be difficult

Plan difficult encounters

Use sensory manipulation to help you concentrate

Don't beat yourself up

Join a support group

Learn to tolerate your moods

Find friends who are good for you

Be proud of yourself
Have 'blow-out time' or 'time outs'
... but don't use the diagnosis as an 'excuse' for not trying to change things

... be specific about what helps and what doesn't

... and ask for feedback about when you do things well

.. lists, notes, colour coding, reminders, planning, breaking down goals into manageable tasks

(... or don't go too badly!) . 'OHIO' - only handle it once ... and don't let this get you down ... anticipate problems, then they're easier to avoid or deal with

. music, silence, 'something to fiddle with'

gym, dancing, running, etc.

(... or your parents!)

or start one

without panicking or catastrophising

and use them

yes, really! You're trying to make things better! 
MCO answers

$\begin{array}{lllll}1 \mathrm{a} & 2 \mathrm{~b} & 3 \mathrm{~d} & 4 \mathrm{c} & 5 \mathrm{~d}\end{array}$

\section{Scepticism and anxiety about adult ADHD}

Mental health staff in adult services may be experiencing scepticism and anxiety similar to that felt by colleagues in children's services 30 years ago regarding the validity of the diagnosis of $\mathrm{ADHD}$, the attribution of bad behaviour to mental illness, the role of the pharmaceutical industry and the prescribing of controlled drugs to potentially vulnerable individuals (for a debate giving both sides of the validity argument see: Asherson 2010; Moncrieff 2010). Nevertheless, there is increasing evidence that adult $\mathrm{ADHD}$ is a valid diagnosis and that treatment is of benefit (National Collaborating Centre for Mental Health 2008). A consensus paper has also been published by the European Network Adult $\mathrm{ADHD}$, reviewing diagnosis, assessment and management (Kooij 2010).

Adult mental health services may have less experience in dealing with the developmental model inherent in all neurodevelopmental disorders, including $\mathrm{ADHD}$ and autism-spectrum disorder, and with the fact that ADHD 'symptoms' are not only common in the general population but also not qualitatively different from normal experience. Care needs to be taken that services are efficiently directed at those with significant dysfunction. At a time when services are under pressure to deliver more for less, anxieties about the impact on CMHTs of the increasing diagnosis of adult $\mathrm{ADHD}$ are understandable. Over the past decade, small specialist services for adult ADHD have been developed in some areas, but it is unlikely that this model will be appropriate in all localities.

The Royal College of Psychiatrists (2010) has recommended that consideration be given to enlarging CMHTs to allow a degree of specialism to

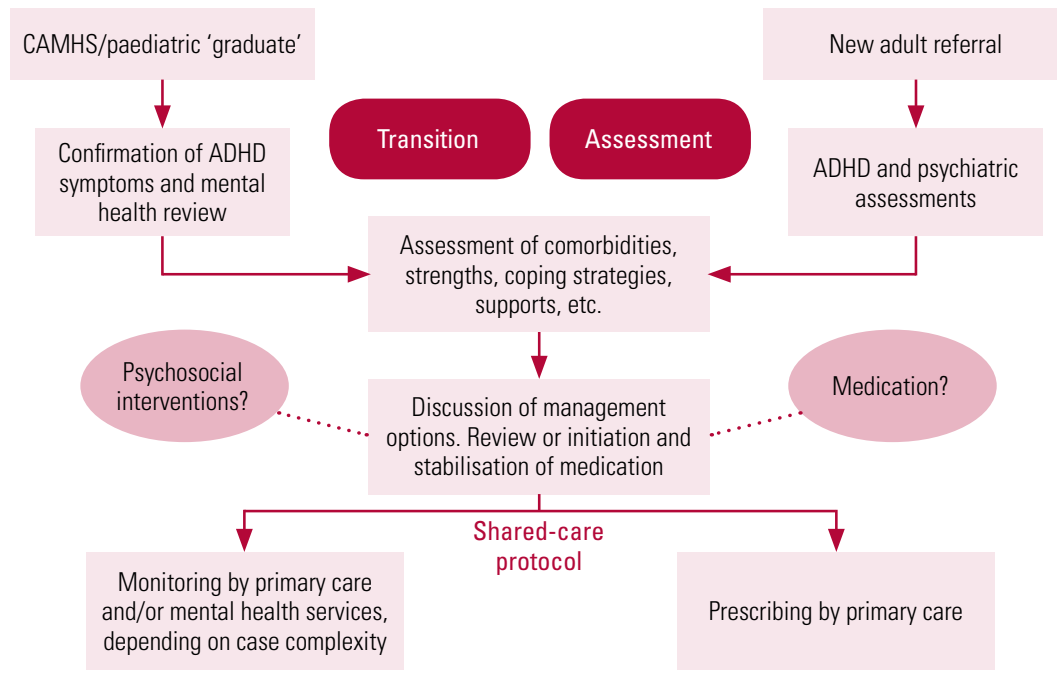

The shared-care protocol of Sheffield Health and Social Care NHS Foundation Trust (reproduced with permission). be embedded within the larger team. Adult ADHD is a relatively common disorder and demand for assessment and treatment is likely to increase over the next decade. With appropriate support and training, an integrated service delivery model with ADHD specialists embedded in the CHMT could be developed to complement dedicated tertiary services. This would provide patients with a local service coordinated with primary care, facilitate the management of comorbid problems, enable a multidisciplinary approach to management, and also be the best method of improving awareness of and familiarity with the disorder.

\section{Acknowledgements}

I would like to thank Dr Andrew McNeill, who sparked my interest in the topic and commented on this article, and Dr Rachel Warner, Clinical Director of Sheffield Health and Social Care NHS Foundation Trust, without whose help the service development would not have been possible. I also thank other colleagues at Sheffield Health and Social Care Trust who have contributed to this work.

\section{References}

Almeida Montes LG, Hernández García A0, Ricardo-Garcell J (2007) ADHD prevalence in adult outpatients with nonpsychotic psychiatric illnesses. Journal of Attention Disorders 11: 150-6.

American Psychiatric Association (1968) Diagnostic and Statistical Manual of Mental Disorders (2nd edn) (DSM-II). APA.

American Psychiatric Association (1980) Diagnostic and Statistical Manual of Mental Disorders (3rd edn) (DSM-III). APA.

American Psychiatric Association (1987) Diagnostic and Statistical Manual of Mental Disorders (3rd edn, revised) (DSM-III-R). APA

American Psychiatric Association (1994) Diagnostic and Statistical Manual of Mental Disorders (4th edn) (DSM-IV). APA.

Asherson P (2005) Clinical assessment and treatment of attention-deficit hyperactivity disorder in adults. Expert Review of Neurotherapeutics 5: 525-39

Asherson P, Adamou M, Bolea B et al (2010) Is ADHD a valid diagnosis in adults? Yes. BMJ 340: $c 549$.

Biederman J, Faraone SV, Spencer TJ, et al (2006) Functional impairments in adults with self-reports of diagnosed ADHD: a controlled study of 1001 adults in the community. Journal of Clinical Psychiatry 67: 524-40.

Bramham J, Young S, Bickerdike A, et al (2009) Evaluation of group cognitive behavioural therapy for adults with ADHD. Journal of Attention Disorders 12: 434-41.

Cumyn L, French L, Hechtman L (2009) Comorbidity in adults with attention-deficit hyperactivity disorder. Canadian Journal of Psychiatry 54: 673-83.

Department of Health (2009) New Horizons - A Shared Vision. Department of Health.

Faraone SV, Biederman J, Mick E (2006) The age-dependent decline of attention-deficit hyperactivity disorder: a meta-analysis of follow-up studies. Psychological Medicine 36: 159-65

Hallowell EM, Ratey JJ (1995) Driven to Distraction: Recognizing and Coping with Attention Deficit Disorder from Childhood through Adulthood. Simon and Schuster.

Harpin VA (2005) The effect of ADHD on the life of an individual, their family, and community from preschool to adult life. Archives of Disease in Childhood 90 (suppl 1): i2-7. 
Kooij SJJ, Bejerot S, Blackwel A, et al (2010) European consensus statement on diagnosis and treatment of adult ADHD: the European Network Adult ADHD. BMC Psychiatry 10: 67 (http://www.biomedcentral. com/1471-244X/10/67)

Mannuzza S, Klein RG (2000) Long-term prognosis in attention-deficit/ hyperactivity disorder. Child Adolescent Psychiatric Clinics of North America 9: 711-26.

Moncrieff J, Timimi S (2010) Is ADHD a valid diagnosis in adults? No. BMJ 340: 0547

McCarthy S, Asherson P, Coghill D, et al (2009) Attention-deficit hyperactivity disorder: treatment discontinuation in adolescents and young adults. British Journal of Psychiatry 194: 273-7.

National Collaborating Centre for Mental Health (2008) Attention Deficit Hyperactivity Disorder: Diagnosis and Management of ADHD in Children, Young People and Adults (NICE Clinical Guideline CG72). National Institute for Health and Clinical Excellence.

Nutt DJ, Fone K, Asherson P, et al (2007) Evidence-based guidelines for management of attention-deficit/hyperactivity disorder in adolescents in transition to adult services and in adults: recommendations from the British Association for Psychopharmacology. Journal of Psychopharmacology 21: 10-41.

Rösler M, Retz W, Thome J, et al (2006) Psychopathological rating scales for diagnostic use in adults with attention-deficit/hyperactivity disorder (ADHD). European Archives of Psychiatry and Clinical Neuroscience 256 (suppl 1): i3-11.

Rösler M, Retz W, Yaqoobi K, et al (2009) Attention deficit/hyperactivity disorder in female offenders: prevalence, psychiatric comorbidity and psychosocial implications. European Archives of Psychiatry and Clinical Neuroscience 259: 98-105

Royal College of Psychiatrists (2010) Looking Ahead: Future Development of UK Mental Health Services. Recommendations from a Royal College of Psychiatrists' Enquiry (Occasional Paper OP75). Royal College of Psychiatrists.

Sheffield Health and Social Care (2010) Adult ADHD: Information and Advice. Sheffield Health and Social Care (http://www.sct.nhs.uk/_ documentbank/SHSC_ADHD_leaflet.pdf).

Simon V Czobor P, Bálint S, et al (2009) Prevalence and correlates of adult attention-deficit hyperactivity disorder: meta-analysis. British Journal of Psychiatry 194: 204-11.
Simonoff E, Pickles A, Charman T, et al (2008) Psychiatric disorders in children with autistic spectrum disorders: prevalence, comorbidity, and associated factors in a population-derived sample. Journal of the American Academy of Child and Adolescent Psychiatry 47: 921-9.

Singh SP (2009) Transition of care from child to adult mental health services: the great divide. Current Opinion in Psychiatry 22: 386-90.

Social Care Institute for Excellence (2011) Case Study: Sheffield ADHD Transitions. Social Care Institute for Excellence (http://www.scie.org.uk/ children/transition/files/Casestudy_ADHD.pdf).

Solanto MV, Marks DJ, Wasserstein J, et al (2010) Efficacy of metacognitive therapy for adult ADHD. American Journal of Psychiatry 167: $958-68$

Taylor N, Fauset A, Harpin V (2010) Young adults with ADHD: an analysis of their service needs on transfer to adult services. Archives of Disease of Childhood 95: 513-7.

Thapar A, Langley K, Asherson P, et al (2007) Gene-environment interplay in attention-deficit hyperactivity disorder and the importance of a developmental perspective. British Journal of Psychiatry 190: 1-3.

Toone BK, van der Linden GJ (1997) Attention deficit hyperactivity disorder or hyperkinetic disorder in adults. British Journal of Psychiatry 170: 489-91.

Ward MF, Wender PH, Reimherr FW (1993) The Wender Utah Rating Scale: an aid in the retrospective diagnosis of childhood attention deficit. American Journal of Psychiatry 150: 885-90.

World Health Organization (1992) The International Statistical Classification of Diseases and Related Health Problems, Tenth Revision (ICD-10). WHO

Young S, Bramham J (2007) ADHD in Adults: A Psychological Guide to Practice. John Wiley \& Sons.

Young S, Wells J, Gudjonsson G (2010) Predictors of offending among prisoners: the role of attention-deficit hyperactivity disorder and substance use. Journal of Psychopharmacology June 17 (Epub ahead of print).

Young SJ, Adamou M, Bolea B, et al (2011a) The identification and management of $A D H D$ offenders within the criminal justice system: a consensus statement from the UK Adult ADHD Network and criminal justice agencies. BMCentral Psychiatry 11: 32 (http://www. biomedcentral.com/1471-244X/11/32).

Young S, Thome J (2011b) ADHD and offenders. World Journal of Biological Psychiatry 12 (suppl 1): 124-8.
MCQs

Select the single best option for each question stem

1 The following characteristics of ADHD are uncommon in adults with the disorder:

a motor overactivity

b impulsivity

c inattention

$\mathrm{d}$ academic underachievement

e risky behaviour.

2 NICE guidelines recommend the following psychological intervention for adult ADHD:

a psychodynamic psychotherapy

b group cognitive-behavioural therapy

c art therapy

d life coaching

e cognitive analytic therapy.
3 As regards treatment of ADHD in adults with moderate impairment:

a stimulants are contraindicated

b atomoxetine should be offered as first-line treatment

c weight and height should be monitored on patients treated with atomoxetine

$\mathrm{d}$ atomoxetine should be avoided in people with high alcohol intake

e methylphenidate may cause weight gain.

4 In the assessment of an adult suspected of having ADHD:

a ADHD can only be confirmed after neuropsychological testing

b the opinion of an adult informant who knew the patient as a child is essential

c the Wender Utah Scale can be used to help in arriving at a clinical diagnosis d concurrent misuse of drugs or alcohol makes assessment impossible

e the presence of a child with AHDH in the family means there is a greater than $50 \%$ chance of the parent having $A D H D$.

5 Young adults who had ADHD in childhood

a need to have a full ADHD assessment in adulthood to confirm the diagnosis

b rarely need to continue with medication

c will generally wish to stop medication

$\mathrm{d}$ often have residual problems of self-esteem

e are likely to misuse stimulant medication if this is prescribed. 